\title{
Modelo para análise da visão da sustentabilidade em pequenas e médias empresas industriais
}

\author{
Roseli Fistarol Krüger \\ Denize Grzybovski*
}

\begin{abstract}
Resumo
O objetivo deste artigo teórico-empírico foi apresentar o modelo mais adequado para identificar a visão de sustentabilidade dos gestores de PMEIs, comparando três modelos que possuem grande consistência na sua construção. Os modelos predominantes, na literatura, sobre sustentabilidade empresarial são os seguintes: Índice de Sustentabilidade Empresarial (ISE), da Bovespa, Grid de Sustentabilidade Empresarial (GSE), de Callado (2010), e as Sete Dimensões da Sustentabilidade (7DS), de Elkington (2012). Trata-se de uma pesquisa exploratória e descritiva, cuja estratégia utilizada foi o estudo de caso único. $\mathrm{O}$ modelo GSE foi considerado de mais fácil entendimento, mas teve limitações relativas ao processo de coleta de dados qualitativos. O modelo de Callado (2010), por sua vez, foi adaptado para a pesquisa qualitativa e resultou em dados qualificados e coerentes com as especificidades das PMEIs.
\end{abstract}

Palavras-chave: Dimensões da sustentabilidade. Pequenas empresas. Sustentabilidade empresarial. Visão.

* Administradora. Especialista em Controladoria e Gestão Empresarial (Unijuí/RS). Especialista em Gestão Estratégica em Cooperativas de Saúde (Unijuí/RS). Mestre em Desenvolvimento (Unijuí/RS). E-mail: rfistarol@gmail.com

** Administradora (URI - Campus Erechim). Professora do Núcleo Docente Permanente do Programa de Pós-Graduação em Administração na Universidade de Passo Fundo (PPGAdm/UPF). Professora Convidada no Programa de Pós-Graduação em Desenvolvimento Regional na Universidade Regional do Noroeste do Estado do Rio Grande do Sul (PPGDR/Unijuí/RS). Membro da Diretoria da Associação Nacional de Estudos em Empreendedorismo e Gestão de Pequenas Empresas (Anegepe). E-mail: gdenize@upf.br

http://dx.doi.org/10.5335/rtee.v23i48.7366

Submissão: 30/08/2016. Aceite: 13/12/2016 


\section{Introdução}

Sustentabilidade empresarial é tema do campo do desenvolvimento, cujo debate iniciou nos anos de 1960, pela perspectiva teórica da responsabilidade socioambiental, contudo, ainda há carências metodológicas na área para a investigação empírica. Pesquisadores e organizações têm adaptado modelos de análise da sustentabilidade socioambiental para a utilização na gestão das organizações (PEREIRA et al., 2011).

O tema é relevante nos estudos organizacionais, pois o cenário empresarial, no que se refere à combinação de questões sociais e ambientais, requer avanços teóricos, desde que a sociedade reconheceu que não bastava somente as organizações responsabilizarem-se pelos aspectos econômicos do empreendimento (DONAIRE, 1999; LEMME, 2010; ZYLBERSZTAJN; LINS, 2010; BARBIERI, 2011), mas também era necessário contemplar suas dimensões social e ambiental (MUNASINGHE, 2007; ELKINGTON, 2012).

O debate sobre sustentabilidade surge de forma mais elaborada no final do século XX (BURSZTYN; BURSZTYN, 2013), ganha maior visibilidade na mídia, no discurso dos intelectuais das diferentes ciências, nas atividades produtivas, nas representações corporativas e na opinião pública em geral. Assim, o tema se tornou uma constante no pensar de diferentes atores sociais, em todas as instâncias da sociedade (ARAGÃO, 2010; BURSZTYN; BURSZTYN, 2013). Há avanços expressivos na proliferação de padrões de sustentabilidade, mas ainda preponderam questões territoriais e limitações de ações, que, em grande medida, estão ligadas a grandes empresas industriais e a determinações presentes nas políticas públicas, como, por exemplo, nas abordagens realizadas por Pires et al. (2014).

Diante dessas proeminências, constata-se que é necessário avançar em direção ao comprometimento real dos empresários das pequenas e médias empresas industriais (PMEIs), uma vez que a preocupação com problemas ambientais e sociais não se refere a uma repentina consciência, mas a apreensão de conhecimentos em busca de melhor desempenho nos níveis ambiental, social e econômico, considerando os três pilares da sustentabilidade.

O presente artigo argumenta sobre a questão da sustentabilidade nas PMEIs, contextualizando a visão dos empresários no que se refere à importância da sustentabilidade e a sua interação com o meio empresarial. Buscou-se identificar o modelo mais adequado de sustentabilidade para os gestores de PMEIs a partir do estudo comparado de três modelos, que possuem grande consistência na sua construção. Aquele considerado mais adequado para PMEIs foi adaptado e testado 
empiricamente em uma empresa industrial, a fim de identificar a visão de sustentabilidade do gestor e de melhorar limitações metodológicas do modelo.

\section{Fundamentação teórica}

\subsection{Sustentabilidade empresarial}

O tema sustentabilidade gerou, até então, estudos contextualizados e com diferentes abordagens teóricas, mas ainda prepondera a abordagem territorial da sustentabilidade, retratando particularidades de comunidades e políticas sociais (RIBEIRO; BARCELLOS; ROQUE, 2013; TREVISAN; LEÃO, 2014; WILDHAGEN, 2015). O Quadro 1 apresenta a evolução das discussões sobre sustentabilidade e está dividido temporalmente em décadas.

Quadro 1 - Evolução das discussões sobre sustentabilidade

\begin{tabular}{|l|l|}
\hline Década & \multicolumn{1}{c|}{ Acontecimento } \\
\hline 1960 & Discurso teórico inicial sobre responsabilidade socioambiental. \\
\hline 1970 & $\begin{array}{l}\text { Ampliação do espaço de reflexão crítica sobre desenvolvimento nas dimensões eco- } \\
\text { nômica e social. Introdução, na agenda internacional com a Conferência das Nações } \\
\text { Unidas em Estocolmo, das discussões sobre sustentabilidade. }\end{array}$ \\
\hline 1980 & $\begin{array}{l}\text { Publicação do Relatório Brundtland (1987), que difunde a ideia de desenvolvimento } \\
\text { sustentável. Também denominado de Nosso Futuro Comum, ele trouxe o imperativo } \\
\text { de "busca de felicidade" e o princípio da perenidade da vida com o compromisso às } \\
\text { futuras gerações. }\end{array}$ \\
\hline 1990 & $\begin{array}{l}\text { Introdução progressiva da sustentabilidade, interação entre as áreas pública e priva- } \\
\text { da nas escolhas de políticas ambientais e envolvimento da sociedade civil organiza- } \\
\text { da. Lançamento da Agenda 21, em 1992, na Rio-92. }\end{array}$ \\
\hline 2000 & $\begin{array}{l}\text { Lançamento, em 2002, pela Cúpula Mundial sobre o Desenvolvimento Sustentável, } \\
\text { em Johannesburgo, dos documentos consolidados na Declaração Política e no Plano } \\
\text { de Implementação da Agenda 21. }\end{array}$ \\
\hline $\begin{array}{l}\text { Realização da Rio+20 para o compromisso dos estados e da comunidade com as } \\
\text { grandes mudanças do século XXI. Nessa década, foram mais de 2.800 publicações } \\
\text { com o tema de gestão baseado na sustentabilidade; enquanto que, de 1982 à 1999, } \\
\text { foram somente 169 publicações; e 1.105, entre os anos de 2000 e 2009. Cresceu o } \\
\text { número de publicações de relatórios de sustentabilidade: das 250 maiores empresas } \\
\text { do mundo, 80\% produziram relatórios; e o Brasil foi o líder em publicações na Améri- } \\
\text { ca Latina, com 60 relatórios anuais de sustentabilidade publicados. }\end{array}$ \\
\hline \multirow{2}{*}{2010}
\end{tabular}

Fonte: elaborado pelos autores. 
No âmbito empresarial, a sustentabilidade pode ser considerada uma mudança transformacional que modifica o modo de perceber os impactos dos negócios e o relacionamento da empresa com a comunidade (APPELBAUM et al., 2016). Esse fato induz os gestores a um novo modelo de gestão de negócios, que, no processo de tomada de decisão, leva em conta, além da dimensão econômico-financeira, as dimensões sociais e ambientais (ZYLBERSZTAJN; LINS, 2010).

Assim, a sustentabilidade empresarial diz respeito à forma de fazer negócios e ao tipo de negócios que a empresa almeja desenvolver, influenciando processos produtivos, relacionamentos, prestação de contas e compromissos públicos, bem como quebrando padrões institucionalizados em favor das questões sociais e ambientais (ZYLBERSZTAJN; LINS, 2010). O papel de condutor de tais práticas em torno da visão de sustentabilidade recai ao gestor, como afirma Lozano (2012).

John Elkington, que, nos anos 1995, cunhou a expressão triple bottom line (TBL), reforça a visão tradicional das dimensões sociais, ambientais e econômicas por meio dos três pilares da sustentabilidade. No pilar econômico, é debatido o capital financeiro, físico, humano, intelectual, natural e social das organizações através da análise de aspectos micro e macroeconômicos. Os aspectos microeconômicos são considerados aqueles associados aos resultados econômico-financeiros da empresa. Já os macroeconômicos destacam o bem-estar econômico, seja de um indivíduo, de um município, de uma região, seja de uma sociedade de maneira geral (CALLADO, 2010). Essa dimensão também suporta atividades de produção e desempenha um equilíbrio intersetorial no desenvolvimento econômico (OLIVEIRA; MARTINS, 2005).

No pilar ambiental, o capital natural pode ser visto de duas formas principais: como essencial para a manutenção da vida e da integridade do ecossistema e como renovável ou substituível (ELKINGTON, 2012). Encontra-se presente nas práticas de reciclagem, de redução da geração de resíduos e poluição, de preservação dos recursos naturais, de produção de recursos renováveis e de limitação dos recursos não renováveis (OLIVEIRA; MARTINS, 2005). Conforme Callado (2010), nos debates observados na literatura sobre essa dimensão, são considerados principalmente os aspectos associados aos recursos naturais e às questões voltadas aos impactos causados por ações de empresas a esses recursos.

No pilar social, Elkington (2012) considera o capital humano na forma de saúde, de habilidades e de educação, contemplando medidas mais amplas da saúde da sociedade e do potencial de criação de riqueza. A sustentabilidade social está na busca de equidade na distribuição de renda e de bens, visando diminuir a desigualdade social e promover a igualdade de acesso a recursos, emprego e serviços sociais 
(OLIVEIRA; MARTINS, 2005; MUNASINGHE, 2007). Então, a sustentabilidade empresarial é o constructo formado por três pilares que devem ser supridos de forma simultânea.

Tentativas para conduzir corporações na direção da sustentabilidade geram ações e reações, apoio e resistência, que tem o objetivo de recuperar relações homem-natureza (SOUZA, 2000), ausentes num ambiente econômico e social (DONAIRE, 1999; SOUZA, 2000). No entanto, é preciso envolver atores sociais e grupos para mudar modelos mentais e transformar a cultura empresarial em favor de maior transparência nos negócios e na gestão dos recursos (DONAIRE, 1999; ELKINGTON, 2012).

Aragão (2010) destaca que os empresários estão mais conscientes dos impactos ambientais causados por seus empreendimentos, e o debate sobre responsabilidade socioambiental nas organizações reflete a dimensão ética e moral do comportamento e de valores da sociedade (DONAIRE, 1999). É preciso pensar rentabilidade das empresas, mas não à custa do sofrimento de empregados ou da degradação do ambiente (AKTOUF, 1996). Com esse olhar, a seguir, são analisados os modelos de mensuração da sustentabilidade empresarial.

\subsection{Modelos de mensuração da sustentabilidade empresarial}

Entre os modelos elaborados para mensurar a sustentabilidade empresarial, destacam-se: o Índice de Sustentabilidade Empresarial (ISE), utilizado pelo BM\&FBOVESPA na Bolsa de Valores; o Grid de Sustentabilidade Empresarial (GSE), desenvolvido por Callado (2010); e as Sete Revoluções para a Sustentabilidade (7DS), apresentado por Elkington (2012). Os critérios utilizados para a seleção dos modelos foram: abrangência, consistência metodológica e consideração conceitual dos três pilares da sustentabilidade, o TBL. 
a) Índice de Sustentabilidade Empresarial (ISE)

A tendência mundial de valorização dos conceitos de desenvolvimento sustentável tem sido observada também nos mercados financeiros. A procura por investimentos socialmente responsáveis por parte dos investidores tem incentivado a criação de índices de ações, para identificar e classificar empresas que incorporam esses conceitos em diversos países (SILVA; QUELHAS, 2006; ZAMCOPÉ; ENSSLIN; ENSSLIN, 2012).

O ISE é considerado o índice de sustentabilidade pioneiro na América Latina, foi iniciado em 2005 (BM\&FBOVESPA, 2015) e elaborado pelo Centro de Estudos em Sustentabilidade da Escola de Administração de Empresas de São Paulo, da Fundação Getúlio Vargas, com base em experiências de mensuração de sustentabilidade internacionais (FEIL; NAIME, 2015). A observância desse índice, pelos gestores, contribui para a formação de um ambiente de investimentos compatível com as demandas de desenvolvimento sustentável da sociedade contemporânea e estimulou a responsabilidade ética das corporações (ZAMCOPÉ; ENSSLIN; ENSSLIN, 2012; BM\&FBOVESPA, 2015).

Para avaliação do desempenho das empresas quanto à sustentabilidade é respondido um questionário, que parte do conceito TBL e de suas dimensões ambiental, social e econômica analisadas de forma integrada (MARCONDES; BACARJI, 2010; ZAMCOPÉ; ENSSLIN; ENSSLIN, 2012). Os autores referidos afirmam que não há exclusão sumária de setores econômicos, pois todas as empresas que possuem liquidez mínima definida pelo Conselho do ISE podem responder ao questionário e participar da seleção. O Quadro 2 destaca a estrutura do questionário no período de 2015/2016: 
Quadro 2 - Estrutura do questionário ISE 2015/2016

\begin{tabular}{|c|c|}
\hline Dimensões & Setor \\
\hline Dimensão Geral & Todos os setores. \\
\hline $\begin{array}{l}\text { Dimensão da Natureza } \\
\text { do Produto }\end{array}$ & Todos os setores. \\
\hline $\begin{array}{l}\text { Dimensão de } \\
\text { Governança Corporativa }\end{array}$ & Todos os setores. \\
\hline $\begin{array}{l}\text { Dimensão } \\
\text { Econômico-Financeira }\end{array}$ & Todos os setores. \\
\hline Dimensão Ambiental A & $\begin{array}{l}\text { Setores dos segmentos de: cervejas e refrigerantes; cigarro e fumo; } \\
\text { madeira, papel e celulose; água e saneamento; energia elétrica (gera- } \\
\text { ção e transmissão); açúcar e álcool; agricultura e pecuária (produção). }\end{array}$ \\
\hline Dimensão Ambiental B & $\begin{array}{l}\text { Setores dos segmentos de: artefatos de cobre; ferro e aço; fertilizan- } \\
\text { tes; minerais metálicos; petróleo e gás (exploração e ou refino); petro- } \\
\text { químicos; siderurgia. }\end{array}$ \\
\hline Dimensão Ambiental C & $\begin{array}{l}\text { Setores dos segmentos de: acessórios; fios e tecidos; armas e mu- } \\
\text { nições; automóveis e motocicletas; alimentos diversos; brinquedos } \\
\text { e jogos; calçados; computadores e equipamentos; construção civil; } \\
\text { construção pesada; couro; defensivos; embalagens; equipamentos } \\
\text { elétricos; eletrodomésticos; etc. }\end{array}$ \\
\hline Dimensão Ambiental D & $\begin{array}{l}\text { Setores dos segmentos de: aluguel de carros; serviços de apoio e } \\
\text { armazenagem; transporte aéreo; transporte ferroviário; transporte hi- } \\
\text { droviário; transporte rodoviário; distribuição de combustíveis e gás; } \\
\text { distribuição de energia elétrica. }\end{array}$ \\
\hline Dimensão Ambiental E & $\begin{array}{l}\text { Setores dos segmentos de: comércio de máquinas e equipamentos, } \\
\text { comércio de material de transporte; engenharia consultiva; explora- } \\
\text { ção de imóveis; serviços diversos; intermediação imobiliária; comér- } \\
\text { cio: alimentos, livrarias e papelarias; medicamentos, produtos diver- } \\
\text { sos; tecidos, vestuários e calçados; etc. }\end{array}$ \\
\hline Dimensão Ambiental IF & Instituições financeiras e seguradoras. \\
\hline Dimensão Social & Todos os setores. \\
\hline $\begin{array}{l}\text { Dimensão de Mudanças } \\
\text { Climáticas }\end{array}$ & Todos os setores. \\
\hline
\end{tabular}

Fonte: elaborado pelos autores. 
A análise dos resultados obtidos através do preenchimento do questionário do ISE pode contribuir para a reflexão dos gestores sobre a importância da sustentabilidade nas empresas de capital aberto, visto que somente as empresas que integram a bolsa de valores podem participar do ISE em três categorias:

a) Elegível, é a única categoria que possibilita à companhia integrar a carteira do ISE. Requer o processo completo de respostas ao questionário e de apresentação de evidências após sua submissão à equipe técnica do ISE, que analisa as respostas e faz uma avaliação amostral dos documentos enviados para comprová-las. A decisão sobre a composição da carteira do ISE cabe ao seu Conselho, e o resultado é anunciado ao final de cada ciclo.

b) Treineira, é a categoria na qual as empresas participam parcialmente do processo de seleção e não estão habilitadas a integrar a carteira do ISE. Ao fim do processo, do mesmo modo que as participantes na categoria elegível, cada empresa recebe relatório contendo seu desempenho quantitativo, resultante da pontuação obtida no questionário, tanto em termos absolutos, quanto em relação às demais respondentes.

c) Simulada, é a categoria aberta a todas as empresas listadas na BM\&FBOVESPA. A empresa responde ao questionário do ano anterior e, ao concluir suas respostas, recebe imediatamente o relatório contendo seu desempenho quantitativo em relação àquele ano. Nessa categoria, a empresa pode optar por quais dimensões deseja responder, pois não é obrigatório o preenchimento das sete.

A estrutura das dimensões, dos critérios e dos indicadores, apresenta no Quadro 3, tem o propósito de demonstrar, em aspectos gerais, sua organização de acordo com as divisões. 


\section{DIMENSÃO AMBIENTAL}

Grupo A (nesta dimensão, conforme o Quadro 2, existem indicadores e critérios de acordo com o segmento da empresa respondente).

CRITÉRIO I - POLÍTICA (Indicadores: compromisso, abrangência e divulgação).

CRITÉRIO II - GESTÃO (Indicadores: responsabilidade ambiental, planejamento, gerenciamento e monitoramento, certificações, comunicação com partes interessadas e compromisso global: biodiversidade e serviços ecossistêmicos).

CRITÉRIO III - DESEMPENHO (Indicadores: consumo de recursos ambientais - inputs, emissões atmosféricas, efluentes líquidos e resíduos, aspectos ambientais críticos, seguro ambiental).

CRITÉRIO IV - CUMPRIMENTO LEGAL (Indicadores: área de preservação permanente e cadastro ambiental rural, reserva legal, passivos ambientais, requisitos administrativos, procedimentos administrativos, procedimentos judiciais).

\section{DIMENSÃO ECONÔMICO-FINANCEIRA}

\section{Grupo único}

CRITÉRIO I - POLÍTICA (Indicadores: planejamento estratégico, ativos intangíveis, defesa da concorrência).

CRITÉRIO II - GESTÃO (Indicadores: riscos e oportunidades corporativos, crises e plano de contingência, ativos intangíveis, gestão do desempenho, defesa da concorrência).

CRITÉRIO III - DESEMPENHO (Indicadores: demonstrações financeiras, lucro econômico, equilíbrio do crescimento).

CRITÉRIO IV - CUMPRIMENTO LEGAL (Indicador: história).

\section{DIMENSÃO GERAL}

\section{Grupo único}

CRITÉRIO I - COMPROMISSOS (Indicadores: compromisso fundamental, compromissos voluntários). CRITÉRIO II - ALINHAMENTO (Indicadores: consistência dos compromissos, política de engajamento com partes interessadas, remuneração).

CRITÉRIO III - PERSPECTIVA ESTRATÉGICA (Indicadores: estratégia e posicionamento, cadeia de valor).

CRITÉRIO IV - TRANSPARÊNCIA (Indicadores: relatórios).

CRITÉRIO V - ÉTICA E CIDADANIA (Indicadores: defesa da concorrência, prevenção e combate à corrupção, atuação política).

\section{DIMENSÃO DE GOVERNANÇA CORPORATIVA}

\section{Grupo único}

CRITÉRIO I - PROPRIEDADE (Indicadores: relacionamentos entre sócios, transparência, cumprimento legal, divulgação, governança de controladas, coligadas e/ou subsidiárias).

CRITÉRIO II - CONSELHO DE ADMINISTRAÇÃO (Indicadores: estrutura do conselho de administração, dinâmica do conselho de administração).

CRITÉRIO III - GESTÃO (Indicador: qualidade da gestão). 
CRITÉRIO IV - AUDITORIA E FISCALIZAÇÃO (Indicador: prestação de contas).

CRITÉRIO V - CONDUTA E CONFLITO DE INTERESSES (Indicadores: conduta e conflito de interesses).

DIMENSÃO DE MUDANÇAS CLIMÁTICAS

Grupo único

CRITÉRIO I - POLÍTICA (Indicadores: compromisso, abrangência e divulgação).

CRITÉRIO II - GESTÃO (Indicadores: responsabilidade, gestão da mitigação, gestão da adaptação, sistemas de gestão).

CRITÉRIO III - DESEMPENHO (Indicador: Resultados).

CRITÉRIO IV - RELATO (Indicador: Divulgação).

DIMENSÃO DA NATUREZA DO PRODUTO

Grupo único

CRITÉRIO I - IMPACTOS PESSOAIS DO USO DO PRODUTO (Indicador: Riscos para o consumidor ou terceiros).

CRITÉRIO II - IMPACTOS DIFUSOS DO USO DO PRODUTO (Indicadores: riscos difusos, observância do princípio da precaução).

CRITÉRIO III - CUMPRIMENTO LEGAL (Indicadores: informações ao consumidor, sanções judiciais ou administrativas).

DIMENSÃO SOCIAL

Grupo único

CRITÉRIO I - POLÍTICA (Indicadores: compromisso com princípios e direitos fundamentais nas relações de trabalho, compromisso com a comunidade, respeito à privacidade, uso da informação e de marketing).

CRITÉRIO II - GESTÃO (Indicadores: aplicação dos compromissos com princípios e direitos fundamentais nas relações de trabalho, relação com a comunidade, relação com clientes e consumidores).

CRITÉRIO III - DESEMPENHO (Indicadores: diversidade e equidade, gestão de fornecedores, resolução de demandas de clientes e consumidores).

CRITÉRIO IV - CUMPRIMENTO LEGAL (Indicadores: público interno, clientes e consumidores, sociedade).

Fonte: adaptado de BM\&FBOVESPA (2015).

Conforme já destacado, ao final do processo de respostas ao questionário, a empresa participante recebe um relatório com seu desempenho em cada indicador. De acordo com Correia (2013), o ISE pode ser usado como uma ferramenta de gestão, visto que, com o relatório de desempenho, é possível construir uma agenda empresarial interna, relacionada à sustentabilidade, com vistas a atingir maior pontuação nos indicadores que fazem parte do Índice de Sustentabilidade Empresarial da BM\&FBOVESPA. 
b) Sete Dimensões para a Sustentabilidade (7DS)

O modelo 7DS tem sua origem nos estudos desenvolvidos por John Elkington, para investigar as dimensões do desenvolvimento sustentável nas práticas das empresas de petróleo e gás (ELKINGTON, 2012; ALVARENGA et al., 2013). Desde então, o planejamento estratégico das empresas passou a ser pensado a partir das dimensões econômicas, sociais e ambientais (ELKINGTON, 2012), as quais são divididas em: (1) mercados; (2) valores; (3) transparência; (4) tecnologia do ciclo de vida; (5) parcerias; (6) tempo; e (7) governança corporativa. Levando em consideração essa divisão e a quantidade de questões sobre cada assunto, foi elaborado o Quadro 4 para melhor apresentar a distribuição dos temas do modelo.

Quadro 4 - Dimensões e quantidade de questionamentos

(continua)

\begin{tabular}{|c|c|}
\hline Dimensões & Temas dos questionamentos \\
\hline Governança & $\begin{array}{l}\text { parte do entendimento da existência de comitês de sustentabilidade consti- } \\
\text { tuídos; } \\
\text { compromisso versus interesse imediato; } \\
\text { cidadania corporativa versus vantagem competitiva; } \\
\text { cstratégia competitiva da linha dos três pilares; } \\
\text { aspectos mais importantes e potencialmente controversos da gestão; } \\
\text { indicadores de desempenho setorial, de cadeia de valor e de mercados; } \\
\text { alto escalão responsável pela integração e pelo direcionamento para os três } \\
\text { pilares; } \\
\text { códigos voluntários de conduta assinados; } \\
\text { programas de aprimoramento contínuo; } \\
\text { equilíbrio entre conselho, e desafio entre seus diretores. }\end{array}$ \\
\hline Tempo & $\begin{array}{l}\text { tensão entre tempo "largo" e "longo" e o desempenho; } \\
\text { impacto que a sustentabilidade causará na empresa, na indústria e nos mer- } \\
\text { cados; } \\
\text { aumento ou diminuição da escala de tempo relacionada aos nossos negócios; } \\
\text { deslocamento do enfoque da extração para a restauração ambiental; } \\
\text { investimentos, pesquisa e desenvolvimento de escalas de tempo de produtos; } \\
\text { reversão de situações em que não é compensador a linha dos três pilares. }\end{array}$ \\
\hline Parceiras & $\begin{array}{l}\text { poder de "2 + } 2=50 \text { " das "alianças estranhas"; } \\
\text { entendimento dos parceiros quanto ao desafio da linha dos três pilares; } \\
\text { vantagem competitiva a partir do estabelecimento de parcerias com stakehol- } \\
\text { ders; } \\
\text { confirmação de parceiros da existência da prática do "pregado"; } \\
\text { escolha de parceiros estratégicos na linha dos três pilares; } \\
\text { desenvolvimento e sustentação dos relacionamentos; } \\
\text { construção de pontes e acompanhamento de parceiros; } \\
\text { ação dos clientes e concorrentes no engajamento stakeholders. }\end{array}$ \\
\hline
\end{tabular}


(conclusão)

\begin{tabular}{|l|l|}
\hline \multirow{5}{*}{ Ciclo de Vida } & $\begin{array}{l}\text { responsabilidades além dos muros da fábrica; } \\
\text { ciclo de vida, projeto voltado o meio ambiente e ecologia industrial; } \\
\text { ciclo de vida a partir das lentes da linha dos três pilares; } \\
\text { vulnerabilidade dos produtos, dos mercados e da cadeia de valor; } \\
\text { teste de necessidade para os principais produtos; } \\
\text { clientes com olhar nas "funções" em vez de nos produtos; } \\
\text { auditoria sobre os riscos externos nos fornecedores estratégicos. }\end{array}$ \\
\hline alto escalão consciente dos desafios; \\
comunicação dos interesses, dos objetivos e do desempenho na linha dos \\
três pilares; \\
mudança de promessa da sustentabilidade para objetivos dos três pilares; \\
comunicação confiável e efetiva, com o objetivo de atingir emoções e percep- \\
ções; \\
melhores práticas emergentes desenvolvidas em outros setores; \\
comparação com os concorrentes (indicadores e benchmarks); \\
internet e as implicações para a transparência das operações.
\end{tabular}

Fonte: elaborado pelos autores.

Na dimensão dos mercados, o foco está nos seus mecanismos; em lugar de medidas de comando e controle, que promovam uma ruptura no eixo central representado pelo governo, passam a ser as empresas aquelas que promovem o desempenho dos objetivos ambientais e da sustentabilidade, abandonando o paradigma da conformidade e abarcando o novo paradigma concorrencial (ELKINGTON, 2012). A dimensão dos valores é considerada fundamental para a transição entre sustentabilidade e aquisição de riquezas, na qual ocorre o deslocamento do paradigma rígido para o maleável. Esse sistema de deslocamento é uma forma de analisar o interesse das futuras gerações, considerando a possibilidade de abandono da relevância dada ao pilar financeiro. 
Na dimensão da transparência, Elkington (2012) afirma que, durante anos, as organizações resistiram às ações em favor de maior transparência em áreas como a proteção ambiental e outras prioridades da linha de TBL. Entretanto, as questões ambientais se tornam de alta visibilidade e, à medida que o mercado se torna mais globalizado, os segredos comerciais ficam mais relevantes. Isso implica a análise da sustentabilidade pela dimensão da tecnologia do ciclo de vida, propondo o abandono do paradigma do produto e a escolha pelo paradigma da função.

Outra dimensão analítica, a das parcerias, é proposta por Elkington (2012), considerando que, gradativamente, as organizações serão colocadas em um esquema interligando entre governo, indústria e sociedade civil organizada. A parceria potencializa processos tradicionais para alcançar objetivos que nenhum parceiro conseguiria individualmente. A dimensão de parcerias transcende o paradigma da subversão para o da simbiose.

A dimensão do tempo parte do antigo paradigma mais largo para o novo paradigma mais longo, parte das organizações para as organizações-economia-sociedade. No entanto, essa proposta implica outra mudança, representada pela dimensão da governança, que inclui a mudança do paradigma da exclusão para o da inclusão.

Neste sentido, as novas formas de capitalismo vão se desenvolvendo, e os stakeholders necessitarão que as organizações desenvolvam maneiras muito mais "inclusivas" de estabelecer diálogos em diversas vias. A opção é conduzir uma auditoria de sustentabilidade e solicitar aos principais stakeholders que auxiliem no processo.

c) Grid de Sustentabilidade Empresarial (GSE)

Os estudos realizados por Callado (2010) e Callado e Fensterseifer (2010) consistiram numa proposta de integração dos instrumentos de verificação dos aspectos ambientais, sociais e econômicos para a mensuração de sustentabilidade empresarial. O resultado foi um modelo tridimensional da sustentabilidade, o GSE.

$\mathrm{Na}$ construção desse modelo, foi elaborada uma lista de 463 indicadores de sustentabilidade, a partir de uma revisão da literatura, e foram excluídos aqueles repetidos, gerando uma nova lista com 435 indicadores (CALLADO, 2010). O próximo passo foi consultar dez especialistas, que elegeram os indicadores considerados relevantes à mensuração de sustentabilidade. Com o peso atribuído pelos especialistas a cada indicador, Callado (2010) produziu uma lista final com 43 indicadores de sustentabilidade, sendo 16 ambientais, 14 econômicos e 13 sociais.

A mensuração da sustentabilidade empresarial proposta pelo GSE considera uma perspectiva integradora das três dimensões (ambiental, econômica e social) 
da sustentabilidade, que, ao ser associada às quatro faixas distintas de sustentabilidade empresarial propostas, é utilizada para definição dos posicionamentos espaciais no GSE. Através desse grid, torna-se possível posicionar espacialmente uma ou mais empresas, em que o posicionamento I representa o menor desempenho e o posicionamento VII representa as empresas com o melhor desempenho. A Figura 1 representa o posicionamento em cubos.

Figura 1 - Avaliação tridimensional da sustentabilidade e a posição espacial no Grid
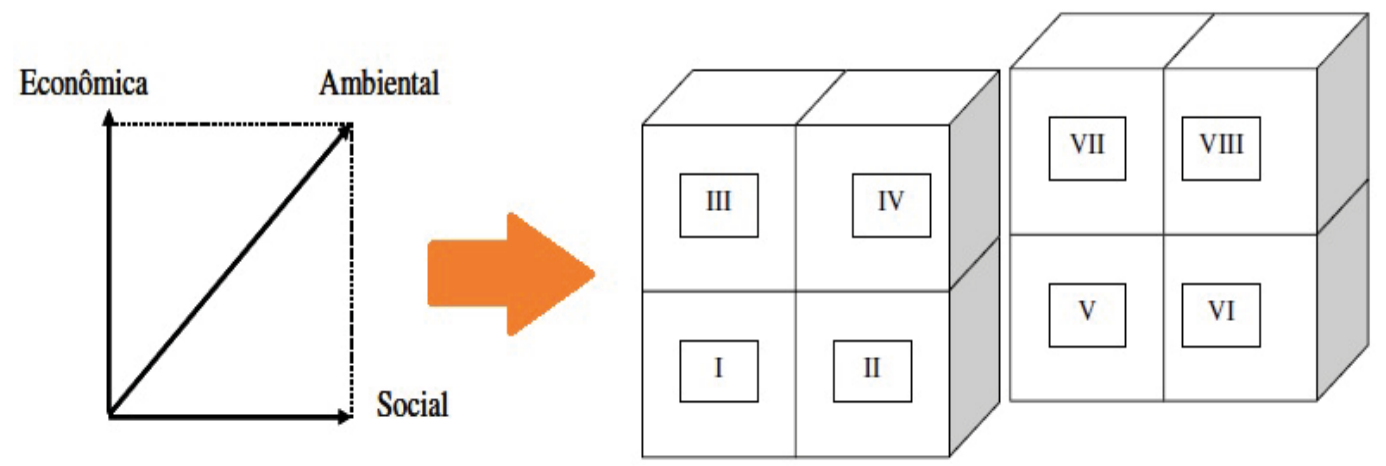

Fonte: adaptada de Callado (2010).

A partir do cálculo do indicador, Callado (2010) identificou se as empresas obtiveram conformidade satisfatória ou insatisfatória em relação a cada uma das três dimensões. A partir disso, foram classificadas as empresas dentro das quatro faixas de sustentabilidade propostas. O posicionamento de empresas no GSE buscou identificar os resultados obtidos a partir de uma perspectiva espacial e tridimensional da sustentabilidade empresarial.

\subsection{Análise comparativa dos modelos de sustentabilidade empresarial}

A análise comparativa buscou compreender a funcionalidade de cada um dos modelos analisados, a fim de selecionar aquele mais adequado à análise da sustentabilidade nas PMEIs. O Quadro 5 sintetiza o estudo comparativo, evidenciando os principais aspectos positivos e negativos dos modelos estudados. 
Quadro 5 - Aspectos positivos e negativos dos modelos de sustentabilidade empresarial

\begin{tabular}{|c|c|c|}
\hline Modelo & Pontos Positivos & Pontos Negativos \\
\hline ISE & $\begin{array}{l}\text { Instrumento consolidado; } \\
\text { Utilização de vários segmentos; } \\
\text { Desempenho disponível para os } \\
\text { clientes; } \\
\text { Grande detalhamento da forma de } \\
\text { aplicação e de pontuação. }\end{array}$ & $\begin{array}{l}\text { Foco em empresa com capital aberto; } \\
\text { Instrumento de coleta complexo para as em- } \\
\text { presas selecionadas neste estudo; } \\
\text { Necessidade de construção de instrumentos } \\
\text { distintos na dimensão ambiental, para estu- } \\
\text { dar PMEls de diferentes segmentos. }\end{array}$ \\
\hline 7DS & $\begin{array}{l}\text { Instrumento conhecido internacio- } \\
\text { nalmente; } \\
\text { Abordagem qualitativa adequada à } \\
\text { proposta deste estudo. }\end{array}$ & $\begin{array}{l}\text { Instrumento com características para utiliza- } \\
\text { ção em grandes organizações; } \\
\text { Necessidade de criação de comitês institu- } \\
\text { cionais para questões da sustentabilidade; } \\
\text { Acompanhamento de indicadores já medidos } \\
\text { e institucionalizados; } \\
\text { Questionamento da criação de políticas inter- } \\
\text { nas e de declarações de valores. }\end{array}$ \\
\hline GSE & $\begin{array}{l}\text { Instrumento elaborado a partir da fu- } \\
\text { são de outros já consolidados; } \\
\text { Participação de dez especialistas na } \\
\text { elaboração do assunto; } \\
\text { Riqueza na explicações dos indica- } \\
\text { dores finais; } \\
\text { Visualização espacial da pontuação } \\
\text { grid; } \\
\text { Disponível para ser usado em em- } \\
\text { presas de diversos segmentos. }\end{array}$ & $\begin{array}{l}\text { Ainda pouco testado; } \\
\text { Abordagem quantitativa, diferentemente da } \\
\text { proposta deste estudo; } \\
\text { Necessidade de adaptação ao modelo de } \\
\text { abordagem qualitativa. }\end{array}$ \\
\hline
\end{tabular}

Fonte: elaborado pelos autores.

Após a análise dos três modelos, aquele que mais apresentou características positivas para a utilização dentro da proposta deste estudo foi o GSE, proposto por Callado (2010). Uma vez que é proveniente de um estudo de indicadores já conceituados nos aspectos da sustentabilidade, demostra riqueza de método e de estudo, tem vasta explicação de cada parâmetro e categoria apresentada, e os resultados alcançados apontam para um instrumento consistente.

Contudo, o modelo de análise permite acessar a sustentabilidade na sua dimensão quantitativa, por esse motivo foi necessário ajustá-lo para um instrumento de pesquisa qualitativa, com vistas a identificar a visão da sustentabilidade empresarial em PMEIs. Após a adaptação do modelo GSE para a abordagem qualitativa, o desafio foi aplicá-lo em uma empresa industrial de um município do noroeste do estado do Rio Grande do Sul e verificar se foi possível acessar a visão de sustentabilidade do gestor. 


\section{Metodologia}

Trata-se de uma pesquisa exploratória e descritiva, desenvolvida pela estratégia de estudo de caso único (YIN, 2005). O método de análise dos dados considerado adequado nesse tipo de estudos é a análise de conteúdo (BARDIN, 2011; MOZZATTO; GRZYBOVSKI, 2011), com triangulação de fontes (YIN, 2005; GIL, 2008).

O caso selecionado para estudo foi o da empresa Vida Doce (nome fictício). É uma empresa de médio porte que atua no ramo da indústria alimentícia há 97 anos, com propriedade e administração familiar e capital fechado. A unidade industrial tem $3.000 \mathrm{~m}^{2}$ e está localizada no distrito industrial de um município do estado do Rio Grande do Sul. Em 1997, a indústria tinha capacidade produtiva de 10 t/mês, gerava cerca de trinta empregos diretos e estava instalada em sede alugada, no centro do município. Atualmente a capacidade produtiva é de $470 \mathrm{t} / \mathrm{mês}$, e a empresa gera 150 empregos diretos. Com maior capacidade produtiva, a Vida Doce expandiu o mercado de atuação para todas as regiões do Brasil e para a América do Sul, exportando para Venezuela, Paraguai, Uruguai, Cuba, Peru, Bolívia e Chile. Essas características tornam-na um caso representativo para o estudo proposto.

Os sujeitos consultados para o desenvolvimento da pesquisa foram o gestor da empresa (G1) e o responsável pela produção e gestão ambiental (R1). G1 trabalha há 18 anos na empresa, é responsável pela gestão geral da produção, do mercado, da contabilidade e da controladoria e foi indicado, pela proprietária, como o principal integrante e representante da visão estratégica da empresa. $R 1$ é responsável pela produção e gestão ambiental, tendo como suas principais atribuições o controle de escalas, a minimização dos desperdícios de produção, o cumprimento das normas da Fundação Estadual de Proteção Ambiental (Fepam), o monitoramento das cisternas, a coleta seletiva de resíduos e a destinação dos mesmos.

$O$ processo de coleta de dados foi realizado em três fases. Na fase 1 , foram realizadas entrevistas com G1, para conhecer a história da empresa e os pressupostos orientadores da gestão no nível estratégico e compreender a visão de sustentabilidade empresarial a partir deste informante. Na Fase 2, foi realizada a visita à empresa, para identificar suas práticas, conhecer o processo de gestão ambiental e compreender a visão de R1 sobre sustentabilidade empresarial. Nessa fase, além da entrevista, os dados foram coletados também por meio de observação não participante. Na fase 3, caracterizada pela pesquisa documental, os dados relativos ao consumo de recursos ambientais (água, energia elétrica, combustíveis fósseis), às práticas com os recursos financeiros (relatórios de controle financeiro e de investimentos e avaliação de desempenho) e à dimensão social (gastos com planos 
de saúde e com programas direcionados aos colaboradores e à sociedade) foram coletados em um formulário específico.

Todas as entrevistas foram gravadas e transcritas de forma fidedigna para garantir a correta leitura dos elementos linguísticos utilizados pelos entrevistados. Ao final das transcrições, as gravações foram destruídas.

O procedimento de análise dos dados utilizado para a entrevista foi à análise de conteúdo, como orientam Bardin (2011) e Mozzato e Grzybovski (2011), Considerou-se também as recomendações de Flick (2009) e de Minayo (2001), com vistas a auferir significação aos dados coletados. As fases da análise de conteúdo realizadas foram as seguintes: pré-análise (A), exploração do material (B) e tratamento dos resultados obtidos e interpretação $(\mathrm{C})$.

A fase de pré-análise (A) consistiu na realização da leitura flutuante (BARDIN, 2011) das entrevistas e dos documentos, a fim de codificar os temas em unidade de registro, atendendo à regra de recorte do sentido, que busca descobrir os "núcleos de sentido" que compõe o discurso (BARDIN, 2011). Esse método buscou transformar os dados brutos dos textos em recortes que permitiram uma representação do conteúdo e de sua expressão. A unidade de contexto utilizada foi o parágrafo, no qual o entrevistado falava sobre o tema (BARDIN, 2011).

Também foram utilizados documentos como unidades de registro (relatório, foto, relato e documentos administrativos), pois se entende que o ponto de interseção de unidade perceptível (documento material, personagem física) e de unidade semântica (temas, acontecimentos, indivíduos) pode revelar a existência de correspondência (BARDIN, 2011; GIL, 2008).

Na sequência, foi realizada a exploração do material (B), que resultou na identificação das dimensões mencionada pelo entrevistado e realizada pelo entrevistador. Por exemplo, em uma pergunta sobre a dimensão ambiental, o entrevistado utilizava vantagens econômicas (redução do desperdício de matéria-prima) para explicá-la. Esses "encontros temáticos" foram interpretados como constituidores da sustentabilidade empresarial e representados graficamente na Figura 2. 
Figura 2 - Proposta de representação da visão de sustentabilidade empresarial

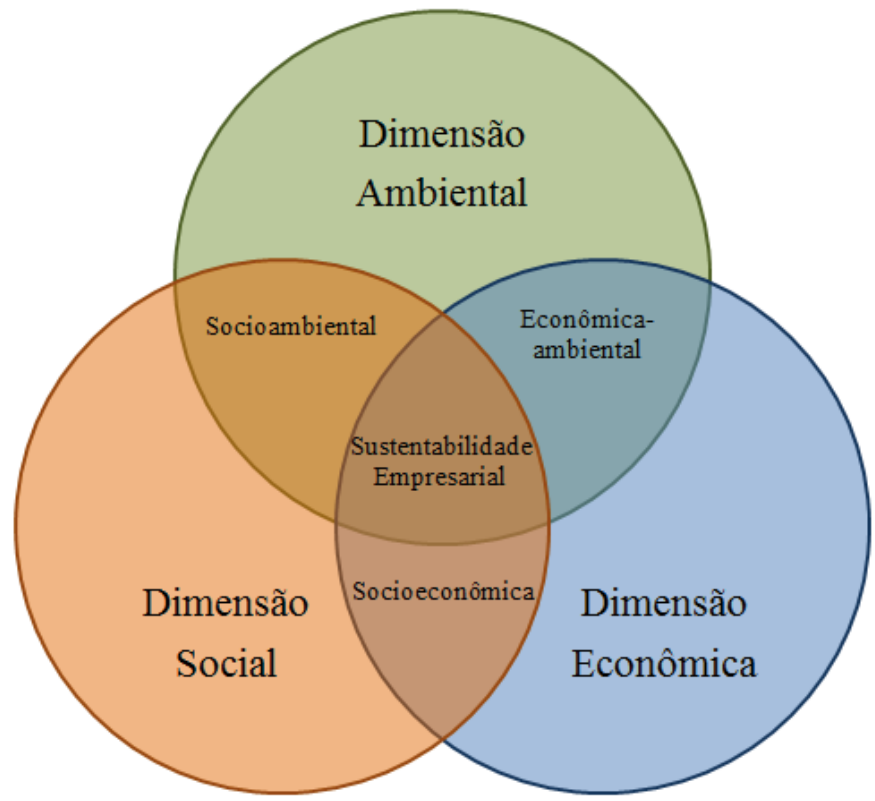

Fonte: elaborada pelos autores.

Com base no exposto, a visão de sustentabilidade é decorrente de encontros temáticos, identificados como socioeconômico, socioambiental e econômico-ambiental, configurando-se em um novo modelo analítico do tema no contexto das pequenas empresas.

Como técnica de análise dos dados, foi utilizada a análise das relações através da coocorrência (BARDIN, 2011) das variáveis socioeconômica, econômico-ambiental e socioambiental ou, puramente, das variáveis social, ambiental e econômica. Segundo Bardin (2011), essa análise procura extrair do texto as relações presentes entre os elementos da mensagem, que ocorrem de forma simultânea dentro da mesma unidade de contexto, conforme explicado nas fases de pré-análise (A) e tratamento dos resultados obtidos e interpretação (C). 


\section{Apresentação e discussão dos resultados}

\subsection{A empresa e suas práticas}

A empresa possui um parque industrial amplo que pode ser usado para expansão estrutural futura. $\mathrm{Na}$ fábrica, os colaboradores têm disponíveis os EPIs e são fiscalizados por R1 quanta à correta utilização. R1 ainda monitora os processos de fabricação no que se refere ao desperdício ou ao mau manuseio de equipamentos ou de produtos.

No setor em que está situada a caldeira, foi verificada a presença de eucaliptos de reflorestamento, empregados exclusivamente na geração de calor para a produção de vapor. $\mathrm{O}$ vapor é gerado com a água de cisterna, captada das chuvas.

A separação de resíduos, como ferro, papelão, plástico e não-recicláveis, é realizada em um prédio separado da indústria. O tratamento de efluentes é realizado por funcionários treinados, e R1 é responsável pelo resultado do processo que tem por objetivo um $\mathrm{pH}$ da água apropriado, para ser destinada ao córrego próximo à fábrica. R1 demonstra, através de seu discurso, entender o processo pelo qual é responsável, contudo, centra-se principalmente na sua parte legal.

As refeições oferecidas aos funcionários são adquiridas prontas de uma empresa terceirizada e são servidas em um prédio separado, mobiliado com mesas e cadeiras, contendo banheiros e um local para descanso e entretenimento. Como alternativa para o traslado residência-trabalho-residência são oferecidas como alternativas de transporte aos funcionários micro-ônibus ou bicicletas, estas adquiridas pela empresa.

Como incentivo à educação continuada, a Vida Doce oferece aos funcionários do setor administrativo incentivos para cursos e graduações. Também disponibiliza plano de saúde de livre adesão com desconto realizado na folha de pagamento.

Em questões econômicas, a empresa realiza periodicamente o acompanhamento do desempenho, tanto contábil como gerencial. A partir dos resultados, são definidos critérios de atuação da equipe de vendas, de produção e de compras. A Vida Doce realizou expansão de venda para o mercado exterior recentemente, a fim de diluir custos fixos de produção e de garantir o retorno dos investimentos realizados. 


\subsection{A visão da sustentabilidade empresarial}

Para G1, sustentabilidade é a capacidade da empresa de gerar riquezas ao mercado sem agredir o meio ambiente. Mesmo utilizando recursos naturais, entende que está produzindo riquezas e, ao mesmo tempo, corrigindo agressões que causam ao meio ambiente. Nas suas palavras:

Sustentabilidade [é] a capacidade de a empresa gerar riqueza, gerar seu produto e dispor no mercado, sem a agressão ao meio ambiente, ou seja, ela é capaz de produzir e ao mesmo tempo, corrigir sem prejudicar a questão ambiental (G1).

Essa abordagem apresenta aspectos de desenvolvimento, quando o gestor cita a geração de riquezas, e também aspectos ambientais sustentáveis, quando menciona a correção a agressões causadas. Essa é uma contradição da lógica de ação, já apresentada por Aragão (2010), visto que a noção de desenvolvimento envolve dinâmica e movimento, enquanto que a de sustentabilidade remete a uma situação estática, que pressupõe permanência (ZYLBERSZTAJN; LINS, 2010).

Importante destacar que G1, quando questionado sobre a visão de sustentabilidade, referiu-se exclusivamente às visões ambiental e econômica, não abordando a dimensão social. Isso pode revelar que o gestor não considera esta dimensão como parte da sustentabilidade, deixando aparente a abordagem da sustentabilidade que foi, por um longo tempo, muito ligada ao meio ambiente e ao econômico. Para isso é importante destacar as contribuições de Lemme (2010), para quem não existe sistema produtivo bem articulados e em doses adequadas que funcione sem capital financeiro, natural e humano.

Quando G1 foi questionado sobre a sua visão ambiental, comentou que os recursos ambientais são importantes para a vida, tanto para a existência humana como para a das empresas. Assim, se a empresa não cuidar os impactos que causa ao meio ambiente, faltarão recursos nos processos produtivos, que ocasionarão a extinção da empresa. Essa interpretação é baseada na fala de G1, a seguir reproduzida:

Se a empresa não fizer seu papel de cuidar do meio ambiente, e água e enfim... não vai ter recurso para produção, ela não vai gerar riqueza e a empresa vai deixar de existir, então, sem meio ambiente não existe empresa também (G1).

Novamente G1 traz em seu discurso os elementos que compõem o aspecto econômico da sustentabilidade, o mais desenvolvido e conhecido das organizações (DIAS, 2006; CALLADO, 2010; ELKINGTON, 2012). Dias (2006) afirma que as 
organizações devem manter processos produtivos mais limpos, desenvolver cultura organizacional ambiental e adotar postura de responsabilidade ambiental, utilizando estímulos internos e externos.

$\mathrm{R} 1$ confirma que a empresa tem postura responsável ambientalmente, mesmo que apenas no cumprimento das determinações legais. Conforme as determinações da Fepam, mantém unidade de tratamento dos efluentes (que causam danos às águas de superfície), para a reestruturação do $\mathrm{pH}$ da água do processo produtivo, a fim de destiná-la aos rios.

A produção de resíduos tem política (não descrita) voltada para a redução de desperdícios, até mesmo no processo de limpeza, que é realizado a seco primeiro, para após ser utilizado água ou vapor, reduzindo o consumo de água e o volume de efluentes para tratamento. $\mathrm{R} 1$ vê o desperdício como gargalo que provoca o aumento dos custos de produção: a preocupação com o acúmulo de resíduos e de tratamento de efluentes, que influenciam no preço final do produto vendido, evidencia a prioridade da visão econômica dentro dos aspectos ambientais.

Foram diagnosticadas reduções lineares do consumo de energia elétrica no processo produtivo, apesar do aumento na produção em toneladas. Esses reflexos foram atribuídos, por R1, às atividades de treinamento e de conscientização realizadas na empresa:

A principal fonte de energia da empresa é o vapor que é usado no cozimento e na higienização a partir de água e lenha de eucalipto na caldeira, portanto, para o processo produtivo não há utilização de combustíveis fósseis, somente para a área de logística (R1).

De acordo com G1, a empresa desenvolveu um projeto de implantação de uma planta industrial que utilizasse energia solar, mas, naquele momento, a empresa não possuía o que era demandado de investimento. Atualmente, eles estão aguardando o momento ideal ou um maior subsídio do governo para desenvolver o projeto. Nesse ponto, observa-se dois elementos, ao questão econômica e a importância do fomento de políticas públicas, voltadas para o investimento em energias limpas.

A empresa já recebeu notificações da Fepam, conforme R1, quanto à qualidade da água destinada ao rio, então houve necessidade de rever o processo de filtragem até a obtenção dos níveis desejados de pH. Contudo, ainda de acordo com R1, a empresa não teve registro de acidente ambiental que fosse atribuído ao seu processo produtivo no último ano.

Para G1, a visão social da empresa é representada pela geração de empregos e de renda, o que revela uma preocupação intrínseca do empresário com a dinâmica socioeconômica do território, conforme revela: 
Hoje é a geração de emprego e renda, não existem outras atividades ainda né... mas a gente é bem consciente sobre isso sobre a questão do meio ambiente, toda a direção ela sempre mostro querer operacionalizar ideias que possam aproveitar a luz do sol, por exemplo, a energia, então que isso tudo isso pode ocasionar, desde que gerar uma energia melhor para ela, vai ajudar o meio ambiente e favorece a comunidade como um todo (G1).

Alguns treinamentos que atualmente acontecem na indústria são específicos para a produção. Contudo, a experiência adquirida nos treinamentos de boas práticas de produção pode ser aproveitada em outras atividades que o funcionário desempenhe em empregos posteriores. Conforme G1, a empresa ainda não trabalha outras questões com os seus colaboradores; contudo, no decorrer dos questionamentos específicos, identifica-se a oferta de benefícios aos funcionários, como transporte, alimentação, cesta básica e plano de saúde e odontológico, que G1 não reconhece como práticas representativas de responsabilidade social.

Para Sachs (1993) e Elkington (2012), objetivo da dimensão social é construir uma civilização que leve mais em conta o "ser" enquanto humano e procura maior equidade na distribuição da renda, com vistas a melhorar os direitos e as condições da população e a reduzir a diferença entre pobres e ricos.

Nesse sentindo, podem-se usar contrições de autores para reconhecer os negócios empresariais como parte da sociedade (ELKINGTON, 2012) e as ações de gestores como cada vez mais monitoradas pelos movimentos sociais (ALMEIDA, 2007; LEMME, 2010; ELKINGTON, 2012), que exigem mais responsabilidade na tomada de decisão.

A empresa participa do programa Empresa Sorriso, desenvolvido pelo Serviço Social da Indústria (SESI), e distribui kits para os funcionários, a fim de disseminar a prática da escovação. Também dispõe de plano de saúde para proprietários e gerentes e oferece-o aos demais funcionários mediante pagamento do valor integral da mensalidade.

Entendemos que pode ser considerado um beneficio, pois o plano de saúde empresarial é mais barato do que se for adquirido de forma individual e por este motivo oferecemos aos funcionários (G1).

Como incentivo ao aperfeiçoamento, a empresa também contribui pagando curso superior aos funcionários do setor administrativo que desejam fazê-lo na área de interesse da empresa. Quanto à parte da produção, são oferecidos treinamentos pertinentes à função do colaborador.

Não foi implantado ainda a participação dos funcionários nos lucros da empresa, porque essa passou por cisão e por um momento economicamente difícil, que impediu a distribuição de lucros. 
O quadro funcional é formado exclusivamente por pessoas da comunidade local. Para os funcionários que não têm transporte próprio, a empresa disponibiliza um micro-ônibus ou fornece bicicletas a eles. Ação responsável, assim descrita pelo empresário:

Damos a preferência para [contratar] as pessoas que residem próximas da indústria. É dada esta preferência, mais por causa da logística, para evitar que os funcionários precisem acordar de madrugada, em função das escalas de serviço (G1).

A empresa disponibiliza cestas básicas aos funcionários regulares, que justificam suas faltas mensais. Esse benefício aumenta conforme o funcionário cumpra essas exigências, podendo seu valor chegar a 180 reais. Quanto à segurança, existe a Comissão Interna de Prevenção de Acidentes - CIPA, e são fornecidos treinamentos e equipamentos de segurança para os funcionários, que são supervisionados para a correta utilização deles, conforme determinações legais trabalhistas.

A alimentação durante a jornada de trabalho é entregue pronta aos trabalhadores por uma empresa terceirizada. Na empresa, há um espaço físico para as refeições e o descanso dos funcionários, ainda assim G1 tem intenção de ampliar o conforto dos trabalhadores, disponibilizando pufes, poltronas e equipamentos de jogos. Conforme determina a legislação trabalhista, na folha de pagamento de cada funcionário, são descontados $20 \%$ do valor da refeição, que é considerado por G1 um valor simbólico. Contudo, a concepção de ser humano presente no discurso do empresário evidencia um oportunismo, quando afirma que: "este valor é mais simbólico, para evitar que eles marcam [a refeição] e não vão almoçar” (G1).

Há um compromisso social da empresa, observado no processo de contratação de pessoal. Desde o primeiro dia de trabalho, os trabalhadores são formais ("carteira assinada desde o início do período de experiência”, afirma G1), o que garante a cobertura dos diretos legais e previdenciários a todas as pessoas que fazem parte da empresa.

Com vistas a qualificar as relações sociais no ambiente de trabalho, a Vida Doce está realizando uma pesquisa de clima organizacional, cujos resultados vão orientar o processo decisório no que se refere à dimensão social. Também pretende-se contratar um profissional psicólogo para auxiliar os trabalhadores nos seus conflitos pessoais, de acordo com o interesse individual.

Nas questões que tratam da participação da empresa com a comunidade, é evidenciado que todas as práticas ficam direcionadas às que proporcionam incentivos fiscais, ou seja, participa-se ajudando a comunidade com a realização do reembolso fiscal. Não há uma política que defina de quais atividades à empresa 
participará anualmente, tudo é decido conforme os pedidos da comunidade chegam até a empresa.

E acaba que a comunidade em geral entende que: - Ah! Eu vou pedir para a Vida Doce, coitada das crianças, e a Vida Doce entende isso [...]. Então a Vida Doce acaba oferecendo com $50 \%$ do valor. O nosso produto é barato, mas é o nosso negócio (G1).

Com a descrição dessa prática, percebe-se que a empresa tem uma postura reativa de participação na sociedade, embora não tenha um orçamento financeiro para as atividades comunitárias, procura unir os aspectos compensatórios para contribuir com entidades beneficentes. Contudo, cabe destacar o último comentário de G1: "O nosso produto é barato, mas é o nosso negócio", essa fala remete a uma situação de luta constante pela sobrevivência, que, muitas vezes, pode deixar as empresas mais resistentes em participar financeiramente com a sociedade. Porém, nem sempre a participação tem viés econômico, podendo ser um foco interessante atuar voluntariamente na comunidade.

G1 menciona simplicidade e humildade dos diretores como características da empresa. Os diretores são pessoas simples e próximas dos trabalhadores, que não têm grandes ambições pessoais. A cultura organizacional de "compartilhar prevalece, porque, se eu tenho uma empresa e eu quero crescer a empresa para aumentar os empregos e aumentar a geração de renda, então, é meio que uma cultura comunitária" (G1).

Na visão econômica, a empresa utiliza software desenvolvido especialmente para verificação da viabilidade econômica. Os dados são analisados todos os meses, verificando os custos de produção e comercialização e analisando a ociosidade da fábrica e a influência no resultado final. Por fim, os dados são socializados em reunião, como relata $\mathrm{G} 1$ :

Na reunião com os sócios são apresentados os resultados mensais. São dois relatórios, o gerencial e o contábil. Estas duas ferramentas usam metodologias diferentes então apresentam resultado diferentes, mas os sócios e diretores já entendem porque os valores são diferentes (G1).

Lemme (2010) e Elkington (2012) afirmam que, entre os itens desejados num relatório de contabilidade, estão lucros e perdas, o balanço das atividades produtivas. Entretanto, na perspectiva da sustentabilidade econômica, deve-se analisar os impactos dos custos da empresa a longo prazo, da demanda pelos seus produtos ou serviços, de seus preços e margens de lucro, de seus programas de inovação e de seus "ecossistemas de negócios" (ELKINGTON, 2012, p. 80). 
Nessas análises, a empresa conseguiu identificar que a margem de contribuição por tonelada de produção aumentou nos últimos anos, porém o EBITDA final e o lucro líquido diminuíram. Segundo a análise de G1:

Então, a empresa é economicamente viável, porém nesse momento ela não está gerando lucro, ela gera resultado operacional, mas não lucro líquido. Então tudo isso é devido àquela questão que a gente comentou antes, que precisa vender mais, teve esse investimento e precisa vender mais (G1).

Esta abordagem é interessante, pois, embora a empresa tenha apresentado prejuízo no seu balanço final do ano de 2015, não é considerada inviável economicamente pelos seus proprietários, reforçando a abordagem de Callado (2010), que afirma que a eficiência econômica deve ser avaliada mais em termos macrossociais do que apenas por meios de critérios de lucratividade empresarial. Desta forma, a dimensão econômica, considerada indispensável para o desenvolvimento, passa a internalizar as outras duas dimensões do desenvolvimento sustentável (MUNASINGHE, 2007; CALLADO, 2010; ELKINGTON, 2012).

A participação da empresa no mercado apresentou aumento de $30 \%$ entre 2014 e 2015, que contemplou a evolução no volume vendido e o número de novos clientes abertos. A empresa investiu em viagens e no aumento de gerentes por área, prospectando novos clientes em determinadas regiões do país e também no exterior.

O volume de venda na empresa é medido através do volume versus a abertura de clientes novos ou reativação de clientes, que é realizado a cada 30 ou 45 dias, quando os gerentes se reúnem para avaliar os resultados do período (G1).

Essa prática está ligada à dimensão dos mercados, trabalhada por Elkington (2012), que define o foco nos mecanismos de mercado, com o eixo central nas empresas, o qual promove o desempenho dos objetivos ambientais e da sustentabilidade, abarcando o novo paradigma concorrencial.

No Quadro 6, está representada a visão de sustentabilidade na empresa Vida Doce, realizada com base no modelo proposto por Callado (2010) e considerando as adaptações propostas no presente estudo. 
Quadro 6 - Visão da sustentabilidade na empresa Vida Doce

\begin{tabular}{|c|c|c|}
\hline $\begin{array}{l}\text { Dimensão } \\
\text { em estudo }\end{array}$ & Evidências & Coocorrência \\
\hline da Visão & $\begin{array}{l}\text { "Sustentabilidade [é] a capacidade de a empresa gerar riqueza, } \\
\text { [...], ou seja, ela é capaz de produzir e, ao mesmo tempo, corrigir } \\
\text { sem prejudicar a questão ambiental." (G1) }\end{array}$ & Econômico-ambiental \\
\hline Ambiental & $\begin{array}{l}\text { "Se a empresa não fizer seu papel, que é cuidar do meio ambien- } \\
\text { te, não vai ter recurso para produzir riquezas." (G1) }\end{array}$ & Econômico-ambiental \\
\hline Ambiental & $\begin{array}{l}\text { "O desperdício de recursos é um gargalo nos processos produ- } \\
\text { tivo, prática que provoca aumento dos custos de produção, de } \\
\text { coleta de resíduos e de tratamento de efluentes e influenciam no } \\
\text { preço final do produto." (R1) }\end{array}$ & Econômica \\
\hline Ambiental & $\begin{array}{l}\text { A empresa desenvolveu um projeto de planta industrial que utiliza } \\
\text { energia solar, mas a empresa não possuía o que era demandado } \\
\text { de investimento. }\end{array}$ & Econômico-ambiental \\
\hline Social & $\begin{array}{l}\text { "Alguns treinamentos que hoje acontecem nesta indústria são es- } \\
\text { pecíficos para a produção." (G1) }\end{array}$ & Socioeconômica \\
\hline Social & $\begin{array}{l}\text { "O plano de saúde empresarial é mais barato do que se for adqui- } \\
\text { rido de forma individual e por este motivo oferecemos aos funcio- } \\
\text { nários (por adesão)." (G1) }\end{array}$ & Socioeconômica \\
\hline Social & $\begin{array}{l}\text { "Damos a preferência para [contratar] as pessoas que residem } \\
\text { próximas da indústria. [...] evitar que os funcionários precisem } \\
\text { acordar de madrugada, em função das escalas de serviço." (G1) }\end{array}$ & Socioeconômica \\
\hline Social & $\begin{array}{l}\text { "A empresa disponibiliza cestas básicas para os funcionários que } \\
\text { forem regulares ao trabalho [...], podendo chegar a } R \$ 180,00 . " \text { (G1) }\end{array}$ & Socioeconômica \\
\hline Social & $\begin{array}{l}\text { "A empresa quer investir para colocar alguns jogos, pufes, pol- } \\
\text { tronas no Pub. [...] Simbolicamente } 20 \% \text { do valor da refeição é } \\
\text { descontada do funcionário". (G1) }\end{array}$ & Social \\
\hline Social & $\begin{array}{l}\text { "“O nosso produto é barato, mas é o nosso negócio, por isso } \\
\text { subsidiamos } 50 \% \text { do valor do produto para poder beneficiar mais } \\
\text { entidades". (G1) }\end{array}$ & Socioeconômica \\
\hline Econômica & $\begin{array}{l}\text { "As características da empresa são a simplicidade e a humildade } \\
\text { que é vinda com a gestão [...], tudo o que é gerado na empresa é } \\
\text { revertido para o crescimento da empresa". (G1) }\end{array}$ & Socioeconômica \\
\hline Econômica & $\begin{array}{l}\text { "Na reunião com os sócios são apresentados os resultados men- } \\
\text { sais. São dois relatórios, o gerencial e o contábil [...] metodolo- } \\
\text { gias diferentes são iguais a resultado diferentes, mas os sócios e } \\
\text { diretores entendem". (G1) }\end{array}$ & Econômica \\
\hline Econômica & $\begin{array}{l}\text { "Alguns gerentes e acionistas recebem os relatórios semanal- } \\
\text { mente, então conseguem acompanhar a nossa cobertura de des- } \\
\text { pesas, o EBITDA". (G1) }\end{array}$ & Econômica \\
\hline Econômica & $\begin{array}{l}\text { "A empresa é economicamente viável, porém nesse momento ela } \\
\text { não está gerando lucro [...]. Teve investimentos e precisa vender } \\
\text { mais". (G1) }\end{array}$ & Econômica \\
\hline Econômica & $\begin{array}{l}\text { "O volume de venda na empresa é medido através do volume } \\
\text { versus a abertura de clientes novos ou reativação de clientes an- } \\
\text { tigos." (G1) }\end{array}$ & Econômica \\
\hline
\end{tabular}

Fonte: dados da pesquisa. 
As dimensões analíticas da sustentabilidade empresarial se inter-relacionam e não estão dissociadas dos discursos e das práticas da gestão empresarial. Contudo, as variáveis da dimensão econômica são prevalentes no discurso do gestor da empresa Vida Doce, conforme se observam as incidências no Quadro 7.

Quadro 7 - Visão da sustentabilidade na empresa Vida Doce

\begin{tabular}{|l|c|}
\hline \multicolumn{1}{|c|}{ Variáveis de Coocorrência } & Incidência \\
\hline Econômico-ambiental & 3 \\
Econômica & 5 \\
Socioeconômica & 6 \\
Social & 1 \\
\hline
\end{tabular}

Fonte: dados da pesquisa.

Para representar a visão da sustentabilidade empresarial da Vida Doce, conforme proposto na metodologia deste estudo, foram incluídas as incidências de cada variável de coocorrência na Figura 3. Os elementos mais presentes no discurso de ambos os entrevistados representam uma visão mais inclinada às dimensões socioeconômica ( 6 ocorrências) e econômica ( 5 ocorrências) e nenhuma ocorrência foi identificada nos encontros entre a dimensão ambiental e a social (socioambiental).

Figura 3 - Encontros temáticos na visão da sustentabilidade em PMEls

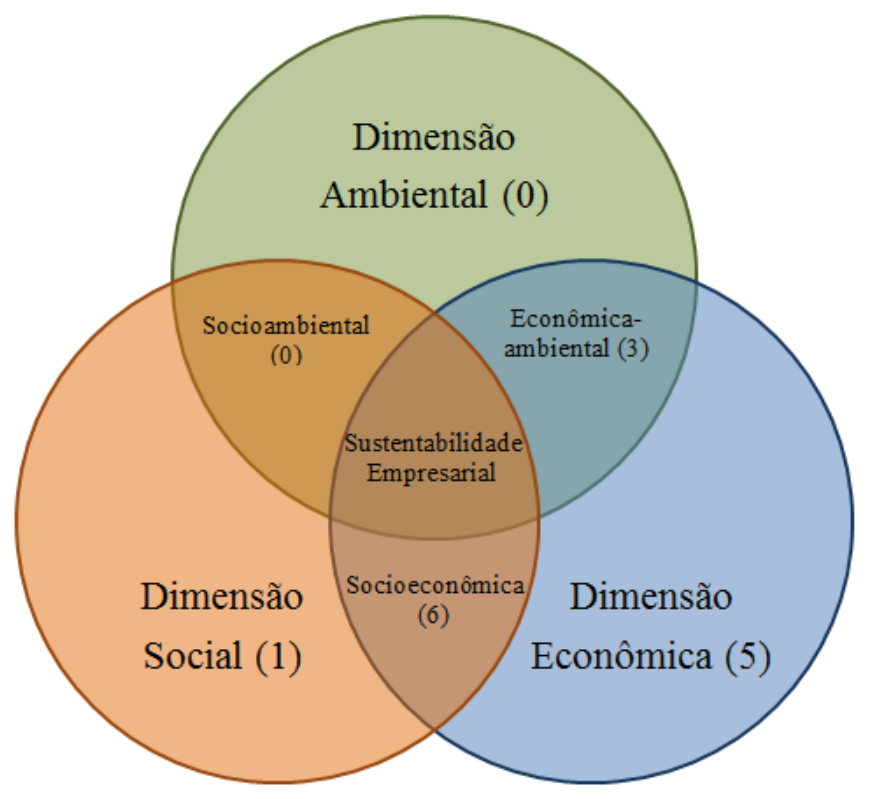

Fonte: elaborada pelos autores. 
Os resultados do estudo realizado na Vida Doce corroboram com o pensamento de Donaire (1999), de que o paradigma funcionalista é o orientador das práticas de gestão. Esse paradigma está pautado na noção de empresa como organização econômica, com foco na maximização dos lucros e na redução dos custos, por vezes ignorando os aspectos sociais e ambientais como variáveis influentes no processo de tomada de decisões.

Há preocupação da empresa estudada com os aspectos ambientais, porém ela caracteriza-se por uma ação decorrente de determinações legais e não por consciência ambiental. Nesse porte de empresa, a pressuposição é de que as práticas de sustentabilidade ambiental estão limitadas à condição econômica empresarial. Não há recursos financeiros para realizar os investimentos necessários, mesmo quando há visão consistente/coerente da sustentabilidade na dimensão ambiental. Constatou-se ainda que a empresa apresentou carência na compreensão dos aspectos social, não os ignora, mas não possui clareza do conceito. Após o debate específico sobre o assunto, várias ações da empresa foram citadas e foi possível fechar a dimensão com riqueza de elementos.

\section{Conclusões}

O modelo GSE de Callado (2010) é útil nos estudos da sustentabilidade empresarial, mas requer adaptações para melhor funcionalidade no contexto das PMEIs, e é limitado para investigar a visão do gestor sobre o tema. Por essa razão, foi elaborado um modelo analítico que capta a inter-relação das dimensões do TBL e suas coocorrências a partir do discurso do gestor.

A principal contribuição do modelo proposto foi a possibilidade de acessar a visão da sustentabilidade empresarial em empresas de qualquer porte. As adaptações realizadas no modelo GSE, de Callado (2010), tornaram o instrumento mais flexível, contribuindo para a captação de elementos subjetivos no discurso do gestor e o trânsito pelas três dimensões do TBL, por meio da identificação dos encontros temáticos socioeconômico, socioambiental e econômico-ambiental. Ao mesmo tempo, o referido modelo evidenciou o distanciamento do discurso do gestor da PMEI em torno do encontro temático resultante da visão de sustentabilidade da dimensão ambiental e da dimensão social.

Nesse sentido, advoga-se em favor da contribuição da abordagem qualitativa dos dados referentes à sustentabilidade empresarial pela troca de informações valiosas durante o processo de coleta de dados, para o entendimento do assunto e para a armazenamento de dados relevantes das diferentes dimensões da 
sustentabilidade. Quando tais dados são tratados a partir da trama discursiva do sujeito participante da pesquisa, a sua qualidade produz registros que não podem ser dissociados das três dimensões da sustentabilidade, que são ambiental, social e econômica.

Identificou-se a visão dos gestores a fim de promover mudanças ou exaltar pontos positivos. A contribuição teórica decorre da elaboração de um instrumento de pesquisa que possibilita acessar a visão da sustentabilidade a partir da abordagem qualitativa. As limitações do estudo relacionam-se à escolha do modelo base, o GSE, de Callado (2010), que se deu a partir da análise comparativa dos instrumentos, sem aplicação prática dos três modelos e, ainda, aplicação do novo modelo em apenas uma PMEIs. Para estudos futuros, indica-se a aplicação do novo instrumento de pesquisa em um maior número de PMEIs, para comprovar a eficiência do modelo.

A abordagem de um caso único pode ser considerada a principal limitação da pesquisa, fato que pode ser usado como proposição para estudos futuros, com maior abrangência de empresas industriais de pequeno e médio porte. 


\title{
Model for analysis of sustainability insight on small and medium industrial enterprises
}

\begin{abstract}
Abtract
The aim of this theoretical and empirical paper was to present the most appropriate model to identify the sustainability vision of PMEIs managers, comparing three models that have great consistency in its construction. The models dominated in the literature on corporate sustainability are: Corporate Sustainability Index (ISE) of the Bovespa Corporate Sustainability Grid (GSE) of Callado (2010) and Seven Dimensions of Sustainability (7DS) of Elkington (2012). This is an exploratory and descriptive research, which strategy used was the single case study. The GSE model is easier to understand, but there are limitations on the collection of qualitative data process. The model Callado (2010) was adapted for qualitative research, resulted in a qualified data and consistent with the PMEIs specifics.

Keywords: Corporate sustainability. Dimensions of sustainability. Small business. Vision.
\end{abstract}

\section{Modelo para el análisis de la visión de sostenibilidad en pequeña y medianas empresas industriales}

\section{Resumen}

El objetivo de este trabajo teórico y empírico fue presentar el modelo más adecuado para identificar la visión de sostenibilidad de los gestores PMEIs, comparando tres modelos que tienen una gran consistencia en su construcción. Los modelos predominantes en la literatura al respecto de la sostenibilidad corporativa: Índice de Sostenibilidad Empresarial (ISE) de la Bovespa, la Cuadrícula Empresarial de Sostenibilidad (GSE) de Callado (2010) y siete dimensiones de la sostenibilidad (7DS) de Elkington (2012). Se trata de una investigación exploratoria y descriptiva, dónde la estrategia utilizada fue el estudio de caso único. El modelo GSE es más fácil de entender, pero tiene limitaciones en el proceso de recolección de datos cualitativos. El modelo Callado (2010) fue adaptado para la investigación cualitativa, tuvo como resultado datos calificados y en consonancia con las características específicas PMEIs.

Palabras clave: Dimensiones de la sostenibilidad. Pequeñas empresas. Sostenibilidad corporativa.Visión. 


\section{Referências}

AKTOUF, O. A administração entre a tradição e a renovação. São Paulo: Atlas, 1996.

ALMEIDA, F. Os desafios da sustentabilidade: uma ruptura urgente. Rio de Janeiro: Elsevier, 2007.

ALVARENGA, R. A. M. et al. Arranjo produtivo local e desenvolvimento sustentável: uma relação sinérgica no município de Marco (CE). Revista de Administração Mackenzie, São Paulo, v. 14, n. 5, p. 15-43, set./out. 2013.

APPELBAUM, S. H. et al. A relationship between corporate sustainability and organizational change (part one). Industrial and Commercial Training, [s.l.], v. 48, n. 1, p. 16-23, 2016.

ARAGÃO, C. Desenvolvimento sustentável: um conceito vital e contraditório. In: ZYLBERSZTAJN, D.; LINS, C. (Org.). Sustentabilidade e geração de valor: a transição para o século XXI. Rio de Janeiro: Elsevier, 2010. Capítulo I.

BARBIERI, J. C. Gestão ambiental empresarial: conceitos, modelos e instrumentos. 3. ed. atual. e ampl. São Paulo: Saraiva, 2011.

BARDIN, L. Análise de conteúdo. Lisboa: Edições 70, 2011.

BM\&FBOVESPA. Índice de Sustentabilidade Empresarial (ISE). 2015. Disponível em: <http:// www.bmfbovespa.com.br>. Acesso em: 05 dez. 2015.

Bem-vindos à plataforma de indicadores do ISE. 2015. Disponível em: <http://indicadores.isebvmf.com.br/>. Acesso em: 05 dez. 2015.

BURSZTYN, M.; BURSZTYN, M. A. Fundamentos de política e gestão ambiental: Caminhos para a sustentabilidade. Rio de Janeiro: Garamond, 2013.

BRUNDTLAND, G. H. (Org.) Report of the World Commission on Environment and Development: our common future. In: WORLD COMMISSION ON ENVIRONMENT AND DEVELOPMENT. General Assembly - United Nations. Oxford: Oxford University, 1987.

CALLADO, A. L. C. Modelo de mensuração de sustentabilidade empresarial: uma aplicação em vinícolas localizadas na Serra Gaúcha. 2010. 216 f. Tese (Doutorado em Agronegócios) - Universidade Federal do Rio Grande do Sul, Porto Alegre, 2010.

CALLADO, A. L. C.; FENSTERSEIFER, J. E. Mensuração de sustentabilidade através do grid de sustentabilidade empresarial (GSE): um estudo no setor vinícola. In: CONGRESSO DA SOBER, 48, 2010, Campo Grande. Anais eletrônicos do... Campo Grande: Sober, 2010. p. 1-20.

CORREIA, V. Nenhuma empresa que faz parte do ISE é sustentável: entrevista com Sonia Favaretto, diretora da BM\&FBovespa. 2013. Disponível em: <http://isebvmf.com.br/index.php?r=noticias/view\&id=263981>. Acesso em: $03 \mathrm{dez} .2015$.

DIAS, R. Gestão ambiental: responsabilidade social e sustentabilidade. São Paulo: Atlas, 2006.

DONAIRE, D. Gestão ambiental na empresa. São Paulo: Atlas, 1999.

ELKINGTON, J. Sustentabilidade, canibais com garfo e faca. São Paulo: Makron Books, 2012.

Teoria e Evidência Econômica - Ano 23, n. 48, p. 222-254, jan./jun. 2017 
GIL, A. C. Métodos e técnicas de pesquisa social. 6. ed. São Paulo: Atlas, 2008.

LEMME, C. F. O valor gerado pela sustentabilidade corporativa. In: ZYLBERSZTAJN, D.; LINS, C. (Org.). Sustentabilidade e geração de valor: a transição para o século XXI. Rio de Janeiro: Elsevier, 2010. Capítulo 3.

LOZANO, R. Towards better embedding sustainability into companies' systems: an analysis of voluntary corporate initiatives. Journal of Cleaner Production, [S.1.], v. 25, p. 14-26, abr. 2012.

MARCONDES, A. W.; BACARJI, C. D. ISE: sustentabilidade no mercado de capitais. São Paulo: Report, 2010.

MOZZATTO, A. R.; GRZYBOVSKI, D. Análise de conteúdo como técnica de análise de dados qualitativos no campo da administração: potencial e desafios. Revista de Administração Contemporânea, Curitiba, v. 15, n. 4, p. 731-747, jul./ago. 2011.

MUNASINGHE, M. Sustainable development triangle. 2007. Disponível em: <http://www. eoearth.org/article/Sustainable_development_triangle>. Acesso em: 06 out. 2015.

OLIVEIRA, N. G. I.; MARTINS, C. H. B. (Org.). Indicadores econômico-ambientais na perspectiva da sustentabilidade. Porto Alegre: FEE, 2005.

PEREIRA, G. M. C. et al. Sustentabilidade socioambiental: um estudo bibliométrico da evolução do conceito na área de gestão de operações. Produção, São Paulo, v. 21, n. 4, p. 610-619, 2011.

PIRES, M. S. et al. Measuring and comparing local sustainable development through common indicators: Constraints and achievements in practice. Cities, [S.l.], v. 39, p. 1-9, ago. 2014.

RIBEIRO, P. J. M.; BARCELLOS, C.; ROQUE, O. C. C. Desafios do desenvolvimento em Miracema (RJ): uma abordagem territorial sustentável de saúde e ambiente. Saúde e Sociedade, São Paulo, v. 22, n. 2, p. 575-589, jun. 2013.

RIO+20. Sobre a Rio+20. 2011. Disponível em: <http://www.rio20.gov.br/sobre_a_rio_mais_20. html>. Acesso em: $06 \mathrm{dez} .2015$.

SACHS, I. Estratégias de transição para o século XXI: desenvolvimento e meio ambiente. São Paulo: Nobel, 1993.

SILVA, L. S. A.; QUELHAS, O. L. G. Sustentabilidade empresarial e o impacto no custo de capital próprio das empresas de capital aberto. Gestão \& Produção, São Carlos, v. 13, n. 3, p. 385-395, set./dez. 2006.

SOUZA, R. S. de. Entendendo a questão ambiental: temas de economia, política e gestão do meio ambiente. Santa Cruz do Sul: Edunisc, 2000.

WILDHAGEN, R. O. Sustentabilidade é atributo de quem? Críticas às práticas de Responsabilidade Social Empresarial a partir de um estudo em território minerador. 2015. 160 f. Dissertação (Mestrado em Administração) - Programa de Pós-graduação em Administração, Pontifícia Universidade Católica de Minas Gerais, Belo Horizonte, 2015.

YIN, R. Estudo de caso: planejamento e métodos. 3. ed. Porto Alegre: Bookman, 2005. 
ZAMCOPÉ, F. C.; ENSSLIN, L.; ENSSLIN, S. R. Desenvolvimento de um modelo para avaliar a sustentabilidade corporativa. Produção, Florianópolis, v. 22, n. 3, p. 477-489, maio/ ago. 2012.

ZYLBERSZTAJN, D.; LINS, C. (Org.). Sustentabilidade e geração de valor: a transição para o século XXI. Rio de Janeiro: Elsevier, 2010. 